\title{
Modifikasi Zeolit Alam Menjadi ZSM-5 Sebagai Penjerap $\mathrm{CO}_{2}$
}

\author{
Modification of Natural Zeolite to ZSM-5 as $\mathrm{CO}_{2}$ Adsorber
}

\author{
Esther Mutiara Santallum Ekklesia Tibalia ${ }^{\mathrm{a}}$, Fatta Hemawatia ${ }^{a}$, Bernadhetta Vivi Kristiana ${ }^{\mathrm{b}}$, Gregorius Prima Indra \\ Budianto $^{\mathrm{a}^{*}}$
}

${ }^{a}$ Teknik Kimia Universitas Setia Budi, Jl. Letjen Sutoyo, Mojosongo, Surakarta, 57127, Indonesia

${ }^{b}$ Teknik Industri Universitas Setia Budi., Jl. Letjen Sutoyo, Mojosongo, Surakarta, 57127, Indonesia

\section{Artikel histori : \\ Diterima 03 Mei 2021 \\ Diterima dalam revisi 04 September 2021 \\ Diterima 04 Oktober 2021 \\ Online 01 November 2021}

\begin{abstract}
ABSTRAK: Biogas merupakan produk dari proses penguraian bahan-bahan organik oleh mikroorganisme dalam kondisi tanpa udara (anaerob). Dari semua unsur biogas yang berperan dalam menentukan kualitas biogas yaitu gas metana $\left(\mathrm{CH}_{4}\right)$ dan gas karbon dioksida $\left(\mathrm{CO}_{2}\right)$. Bila kadar $\mathrm{CH}_{4}$ tinggi maka biogas tersebut akan memiliki nilai kalori yang tinggi, sebaliknya jika kadar $\mathrm{CO}_{2}$ yang tinggi maka akan mengakibatkan nilai kalor biogas tersebut rendah. Salah satu usaha yang dapat dilakukan untuk memurnikan biogas adalah dengan proses adsorpsi semisal dengan zeolit. Dalam rangka meningkatkan efisiensi penjerapan $\mathrm{CO}_{2}$, modifikasi zeolit diperlukan. Pada penelitian ini digunakan zeolit hasil modifikasi yang dikenal dengan ZSM-5. ZSM-5 hasil sintesis memiliki diameter pori yang lebih besar dari pada zeolit alam sehingga diharapkan peningkatan efisiensi penjerapan gas $\mathrm{CO}_{2}$ lebih besar dibandingkan dengan zeolite alam. ZSM-5 yang telah diubah dari zeolit alam akan dibandingkan tingkat efektivitas penjerapan gas dibanding zeolit alam.
\end{abstract}

Kata Kunci: Biogas; adsorpsi; $\mathrm{CO}_{2}$; zeolit alam; ZSM-5

\begin{abstract}
Biogas is a product of the bio-decomposition process in anaerobic conditions. Methane $\left(\mathrm{CH}_{4}\right)$ and carbon dioxide $\left(\mathrm{CO}_{2}\right)$ are the compounds of biogas that act in determining the quality of biogas. When the $\mathrm{CH}_{4}$ level is high, the biogas will have a high caloric value; conversely, the increased $\mathrm{CO}_{2}$ levels result in low biogas heating value. One effort to purify biogas is the adsorption process using natural zeolite. Natural zeolite should be modified into ZSM-5 because it has a greater pore diameter than natural zeolite. It is expected that the increase of the efficiency of $\mathrm{CO}_{2}$ adsorption is more significant than natural zeolite. ZSM-5, which is altered from natural zeolite, will be compared to the effectiveness of $\mathrm{CO}_{2}$ adsorption compared to natural zeolite.
\end{abstract}

Keywords: Biogas; adsorption; $\mathrm{CO}_{2}$; natural zeolite; ZSM-5

\section{Pendahuluan}

Biogas merupakan produk dari proses penguraian bahanbahan organik oleh mikroorganisme dalam kondisi tanpa udara (anaerob). Biogas dihasilkan dari aktivitas bakteri methanogens yang secara alamiah terkandung di dalam limbah yang mengandung bahan organik seperti limbah ternak dan sampah organik (Reniaili, 2014).

Menurut Price dkk. (1981) adapun unsur-unsur yang terkandung dalam biogas yaitu $40-70 \%$ gas metana $\left(\mathrm{CH}_{4}\right)$, $30-60 \%$ gas karbon dioksida $\left(\mathrm{CO}_{2}\right)$, gas oksigen $\left(\mathrm{O}_{2}\right), 3 \%$ gas hidrogen sulfida $\left(\mathrm{H}_{2} \mathrm{~S}\right), 1 \%$ gas hidrogen $\left(\mathrm{H}_{2}\right)$, dan $1 \%$ gas karbon monoksida (CO). Dari semua unsur tersebut yang berperan dalam menentukan kualitas biogas yaitu gas metana $\left(\mathrm{CH}_{4}\right)$ dan gas karbon dioksida $\left(\mathrm{CO}_{2}\right)$. Bila kadar $\mathrm{CH}_{4}$ tinggi maka biogas tersebut akan memiliki nilai kalori yang tinggi. Sebaliknya jika kadar $\mathrm{CO}_{2}$ yang tinggi maka akan mengakibatkan nilai kalor biogas tersebut rendah. Maka dari itu untuk meningkatkan nilai kalor biogas maka kadar gas $\mathrm{CO}_{2}$ harus rendah. Kandungan gas metana $\mathrm{CH}_{4}$ dari biogas dapat ditingkatkan dengan cara memisahkan gas karbon dioksida $\left(\mathrm{CO}_{2}\right)$ yang bersifat korosif dari biogas (Hamidi dkk., 2011). Untuk mengatasi

\footnotetext{
* Corresponding author

Email: greg.budianto87@gmail.com
} 
permasalahan tersebut maka diperlukan proses pemurnian biogas.

Salah satu usaha yang dapat dilakukan untuk meminimalkan gas karbon dioksida $\left(\mathrm{CO}_{2}\right)$ adalah dengan proses adsorpsi. Media adsorpsi yang umum digunakan adalah zeolit karena zeolit merupakan material berpori dan berongga yang mudah didapatkan di alam sehingga harganya relatif lebih murah (Yuanita, 2010; Yulianti, 2017). Berdasarkan Hamidi dkk. (2011), efisiensi zeolit alam dalam menjerap gas $\mathrm{CO}_{2}$ sebesar $17,25 \%$ dari kadar $\mathrm{CO}_{2}$ awal $20 \%$ dan penelitian Ohlin dkk. (2013) mendapatkan nilai penjerapan $\mathrm{CO}_{2}$ sebesar $17,5 \%$. Dalam rangka meningkatkan efisiensi penjerapan $\mathrm{CO}_{2}$, modifikasi zeolit diperlukan.

Pada penelitian ini digunakan zeolite hasil modifikasi yang dikenal dengan ZSM-5. ZSM-5 merupakan yang memiliki rasio $\mathrm{Si} / \mathrm{Al}$ tinggi ( $\mathrm{Si} / \mathrm{Al}$ 5-100) menyerupai zeolit dengan bentuk struktur MFI dan rumus kimia $\mathrm{Na}_{\mathrm{n}}\left(\mathrm{AlO}_{2}\right)_{\mathrm{n}}\left(\mathrm{SiO}_{2}\right)_{96-\mathrm{n}} \cdot 16 \mathrm{H}_{2} \mathrm{O}$ (Petushkov, 2011) sedangkan rasio $\mathrm{Si} / \mathrm{Al}$ zeolite alam paling stabil adalah 5 . Perbandingan Si/Al dalam suatu zeolit akan menentukan kerapatan muatan di dalam kristal. Jika perbandingan besar maka dalam struktur kerapatan muatan akan tinggi, molekulnya polar dan kemampuan untuk mengikat molekul besar akan bertambah, dengan kata lain kapasitas tukarnya tinggi (Emelda, 2013).

Menurut Rohayati (2016), ZSM-5 hasil sintesis memiliki diameter pori yang lebih besar dari pada zeolit alam sehingga diharapkan peningkatan efisiensi penjerapan gas $\mathrm{CO}_{2}$ lebih besar dibandingkan dengan zeolite alam. Penjerapan gas $\mathrm{CO}_{2}$ yang lebih besar dibuktikan dengan penelitian Ayala dkk. (2014) bahwa Na- ZSM-5 dapat diserap sebesar 67,1\%. Penelitian lain oleh Venkatesh (2016) mendapatkan nilai penjerapan gas $\mathrm{CO}_{2}$ menggunakan ZSM-5 sebesar $43 \%$.

Umumnya pembuatan ZSM-5 diperoleh dari kombinasi silika dan alumina yaitu natrium silikat, silikat hidrat, water glass, silika sol, silika gel, clay, silika terpresipitasi dan calcined silica sebagai sumber silika kemudian alumina murni yang dilarutkan dalam $\mathrm{NaOH}$, alumina sulfat, alumina oksida, logam alumina, aluminium hidroksida, aluminium alkoksida, garam-garam aluminium sebagai sumber alumina, seperti yang dilakukan oleh Putro dkk. (2007) menggunakan Al2(SO4)3.18H2O (Merck) dan Zahrina dkk. (2010) menggunakan $\mathrm{Al}(\mathrm{OH})_{3}$ sebagai sumber aluminium. Selain itu, pada proses pembuatannya, ZSM-5 membutuhkan template berupa Tetraprophyl Ammonium Bromide (TPABr). Template ini digunakan untuk mengarahkan struktur ZSM-5 (Kafillah dkk., 2018). Namun, TPABr jarang ditemui dan memiliki harga yang relatif mahal, sehingga proses pembuatan ZSM-5 membutuhkan cost yang sangat tinggi dan menjadi tidak ter kualifikasi secara ekonomi. Oleh karena itu, pada penelitian ini telah dilakukan inovasi pembuatan ZSM-5 menggunakan template CTAB (Cetyltrimethylammonium Bromide) dengan menggunakan bahan baku zeolit alam (mengandung silika dan alumina). Secara lebih mendalam,
ZSM-5 hasil sintesis akan dibandingkan karakteristik dan tingkat efektivitas penjerapan gas dibanding zeolit alam.

\section{Metode Penelitian}

\subsection{Alat dan Bahan}

Alat: Reflux, labu leher tiga, magnetic stirer, hot plate, kertas saring, sonikator, oven, erlenmeyer, neraca analitik, selang, pipa, krus porselen, gas analyzer, $\mathrm{pH}$ meter, desikator, muffle furnace, stamfer \& mortir, alat uji XRD (SHIMADZU XRD-7000) \& SEM (SEM-EDX JEOL JSM-6510LA), dan Gas $\mathrm{CO}_{2}$ (PT. Samator Gas, Solo).

Bahan: Zeolit alam diambil dari Gunung Kidul, $\mathrm{NaOH}$ p.a. (E-Merck), dan CTAB (Cetyltrimethylammonium Bromide) (CV. Chem-Mix Pratama Yogyakarta).

\subsection{Metode}

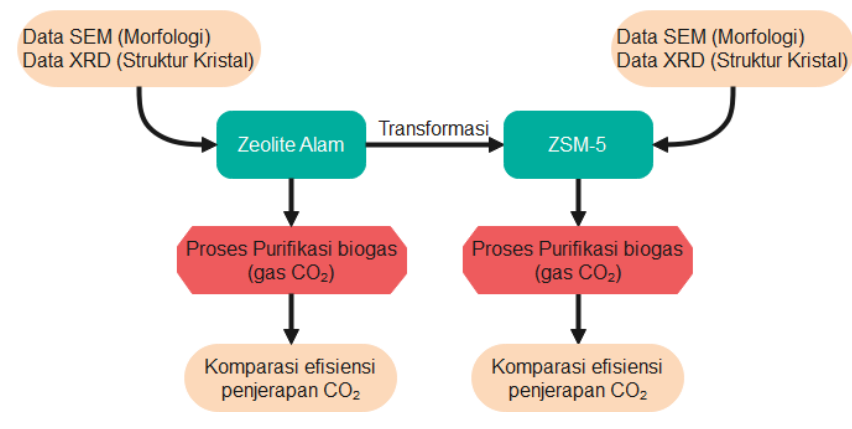

Gambar 1. Prosedur peneltian

Secara garis besar prosedur penelitian disajikan pada Gambar 1, dimana dilakukan dua tahap yaitu:

\section{a. Pembuatan Adsorben:}

\section{Aktivasi Zeolit alam:}

$200 \mathrm{~g}$ zeolit alam diayak dengan ukuran 100 mesh. Setelah itu, zeolite dimaserasi dalam $250 \mathrm{ml} \mathrm{NaOH} 5 \mathrm{~N}$ selama 24 jam. Hasil maserasi selanjutnya disaring untuk diambil endapannya. Endapan zeolit hasil maserasi dicuci dengan akuades sampai $\mathrm{pH}$ 6-8 dan dikeringkan di oven pada suhu $105-110{ }^{\circ} \mathrm{C}$ selama 1 jam lalu disimpan di desikator dalam keadaan tertutup. Selanjutnya, zeolite alam teraktivasi diuji karakteristiknya menggunakan SEM dan XRD

\section{Modifikasi Zeolit menjadi ZSM-5:}

$200 \mathrm{~g}$ zeolit alam diayak dengan ukuran 100 mesh. Selanjutnya dicampur dengan $250 \mathrm{ml} \mathrm{NaOH} 5 \mathrm{~N}$ untuk dilakukan refluks pada suhu $110^{\circ} \mathrm{C}$ selama 3 jam dengan menggunakan kondensor ulir dan air dingin sebagai media pendingin. Setelah proses refluks, campuran didinginkan sesaat dan disaring selagi hangat untuk diambil filtratnya. Selanjutnya, setiap $25 \mathrm{ml}$ filtrat dicampur dengan $1 \mathrm{~g}$ CTAB dan disonikasi selama 10 menit. Setelah itu, campuran dimasukkan ke dalam hydrothermal autoclave dan dipanaskan pada suhu $105{ }^{\circ} \mathrm{C}$ selama 8 jam. Proses selanjutnya adalah pengeringan dan kalsinasi pada suhu $575{ }^{\mathrm{O}} \mathrm{C}$ selama 6 jam. ZSM-5 yang dihasilkan diuji karakteristiknya menggunakan SEM dan XRD. 


\section{b. Uji unjuk kerja zeolit alam teraktivasi dan ZSM-5 dalam menjerap $\mathrm{CO}_{2}$}

Gas $\mathrm{CO}_{2}$ digunakan untuk menggantikan biogas hasil fermentasi karena proses yang lama dan mikroorganisme tidak mampu memproduksi biogas dengan stabil dalam dalam waktu yang singkat. Pada penelitian ini waktu penyerapan divariasikan dalam $5 ; 10 ; 15 ; 20$; dan 25 menit dengan menggunakan adsorben zeolit alam dan ZSM-5, seperti pada Gambar 2.

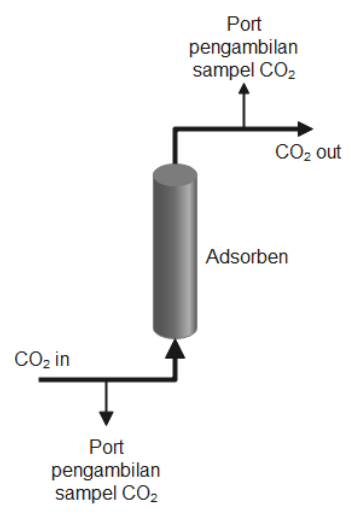

Gambar 2. Proses penjerapan $\mathrm{CO}_{2}$ menggunakan adsorben

\section{Hasil dan Pembahasan}

\subsection{Karakteristik ZSM-5}

SEM dapat digunakan untuk mengetahui morfologi permukaan bahan. Karakterisasi bahan menggunakan SEM dimanfaatkan untuk melihat struktur topografi permukaan dan ukuran butiran.

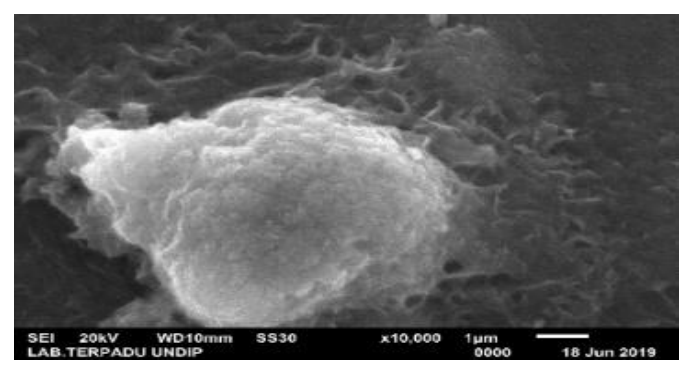

$\mathbf{a}$

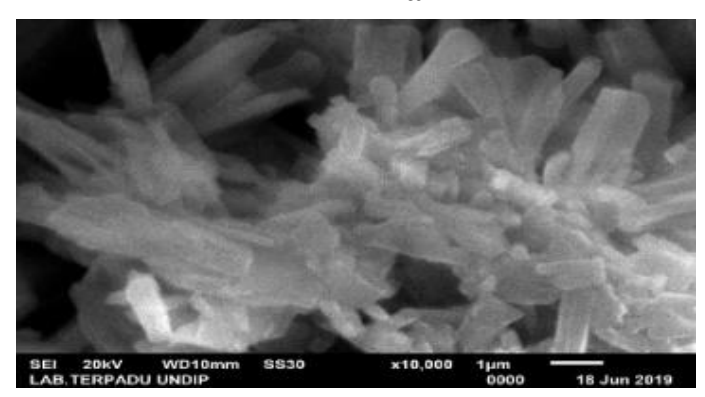

b

Gambar 3. Hasil scanning SEM (a) Zeolit Alam dan (b) ZSM-5 10000X
Hasil yang diperoleh dari karakterisasi ini dapat dilihat secara langsung dari hasil SEM berupa Scanning Electron Moicrograph yang menyajikan bentuk tiga dimensi berupa gambar (Gambar 3).

Ukuran partikel zeolit alam dan ZSM-5 dapat dilihat pada Gambar 3 dengan perbesaran mulai dari 3000X hingga $10000 \mathrm{X}$. Ukuran partikel zeolit alam tidak terukur jelas terlihat bahwa adanya gumpalan pada penampakan morfologinya karena masih adanya zat pengotor lainnya yang tertinggal dan tidak teraktivasi oleh $\mathrm{NaOH}$. Sedangkan ukuran partikel ZSM-5 terlihat jelas kisi antar kristalnya yang membuktikan bahwa metode pembuatan modifikasi zeolit alam menjadi ZSM-5 berhasil.

Difraksi sinar-X digunakan untuk mengidentifikasi struktur kristal padatan dengan rumus perhitungan ukuran kisi kristal baik zeolit alam maupun ZSM-5. Rumus kisi kristal adalah pertama mencari intensitas puncak difraksi dengan data yang telah diketahui pada pengujian. Kemudian dapat mencari nilai jarak (D)/d-spacing (bidang kristal) menggunakan persamaan Dyebe Scharrer yang dirumuskan (Masruroh dkk., 2013):

$$
\begin{aligned}
& T=\frac{\mathrm{a}^{\circ} \times \pi}{180}(1) \\
& D=\frac{k \times \lambda}{T \cos \theta}(2)
\end{aligned}
$$

Keterangan:

$$
\begin{aligned}
& \mathrm{a}^{\mathrm{o}}=\text { Full Width at Half Maximum }(F W H M) \text { (derajat) } \\
& \mathrm{D}=\text { ukuran Kristal }(\mathrm{nm}) \\
& \mathrm{k}=\text { faktor bentuk dari Kristal }(0,9-1) \\
& \lambda=\text { panjang gelombang dari sinar } \mathrm{X}(\mathrm{m}) \\
& \mathrm{T}=\text { nilai dari } F W H M \text { (radian) } \\
& \Theta=\text { sudut difraksi (derajat) }
\end{aligned}
$$

Perhitungan ukuran kisi kristal zeolit alam:

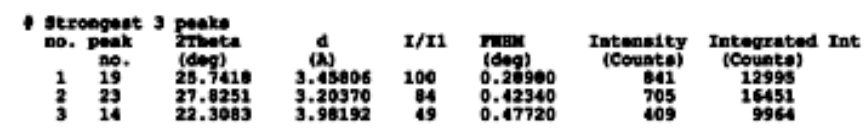

dipilih peak 23:

$$
\begin{gathered}
T=\frac{\mathrm{a}^{\circ} \times \pi}{180}=\frac{0,4234 \times 3,14}{180}=0,007386 \mathrm{rad} \\
D=\frac{k \times \lambda}{T \cos \theta}=\frac{0,9 \times 1,5406 \times 10^{-10}}{0,007386 \times \cos (27,8251)}=20,38 \mathrm{~nm}
\end{gathered}
$$

Perhitungan ukuran kisi kristal ZSM-5:

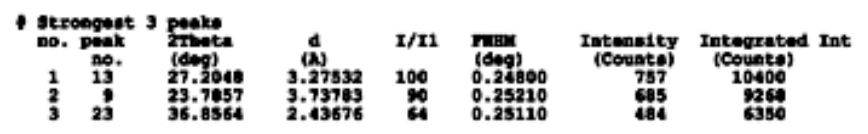

dipilih peak 23 :

$$
\begin{aligned}
& T=\frac{\mathrm{a}^{\circ} \times \pi}{180}=\frac{0,2511 \times 3,14}{180}=0,0043803 \mathrm{rad} \\
& D=\frac{k \times \lambda}{T \cos \theta}=\frac{0,9 \times 1,5406 \times 10^{-10}}{0,0043803 \times \cos (36,5864)}=37,86 \mathrm{~nm}
\end{aligned}
$$




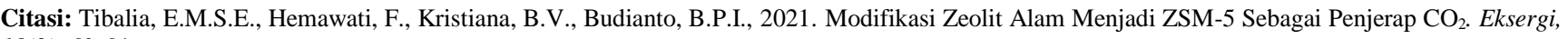
$18(2), 60-64$

Pada data rumus perhitungan ukuran kristal diketahui bahwa ZSM-5 memiliki ukuran kristal yang lebih besar yaitu $37,86 \mathrm{~nm}$ dibandingkan zeolit alam yaitu 20,38 $\mathrm{nm}$ sehingga metode pembuatan modifikasi zeolit alam menjadi ZSM-5 telah berhasil. Selanjutnya juga diketahui grafik ZSM-5 yang digunakan untuk pengukuran kristalinitas relatif yang dilakukan dengan membandingkan jumlah tinggi puncak pada sudut-sudut tertentu dengan tinggi puncak pada sampel standar ZSM-5 yang dapat dilihat pada gambar 4. Kedua grafik dibandingkan dengan melihat jumlah puncak yang sama yaitu pada puncak grafik 0-50. Puncak yang sama tersebut adalah puncak 111 (0-10 degree), puncak 102, 131, dan 022 (10-20 degree), puncak 051, 313, dan 323 (20-30 degree), serta puncak 062 (30-40 degree). Puncak-puncak tersebut membuktikan bahwa modifikasi zeolit alam menjadi ZSM-5 adalah sama dengan ZSM-5 standard.

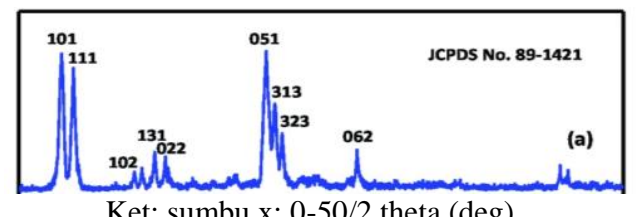

a

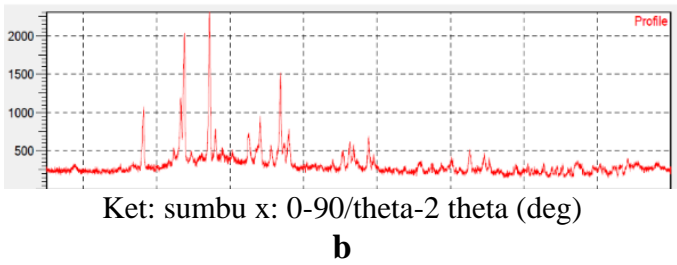

Gambar 4. Grafik (a) XRD ZSM-5 standar dan (b) hasil pengujian

\subsection{Unjuk kerja ZSM-5 pada proses adsorpsi $\mathrm{CO}_{2}$}

Hasil pengukuran $\mathrm{CO}_{2}$ awal tanpa zeolit alam dan menggunakan zeolit alam maupun ZSM-5. Penjerapan $\mathrm{CO}_{2}$ diperoleh dari rata-rata pengurangan antara pengukuran $\mathrm{CO}_{2}$ awal tanpa zeolit alam dengan menggunakan zeolit alam maupun ZSM-5.

Penjerapan $\mathrm{CO}_{2}$ terbaik diperoleh menggunakan ZSM-5 yaitu sebesar 27,5086\% dengan ZSM-5 yang digunakan sebanyak 200 gram sedangkan menggunakan zeolit alam yang telah diaktivasi dengan $\mathrm{NaOH}$ didapatkan sebesar $11,7306 \%$ dengan zeolit alam yang digunakan sebanyak 200 gram. Penelitian ini menunjukkan bahwa penggunaan ZSM-5 lebih efisien dibandingkan dengan zeolit alam. Tabel 1 menunjukkan hasil efisiensi penjerapan $\mathrm{CO}_{2}$ oleh ZSM-5 yang diperoleh dibandingkan dengan hasil efisiensi pada penelitian sebelumnya seperti pada Tabel 1.
Tabel 1. Unjuk kerja beberapa ZSM-5 dalam menjerap $\mathrm{CO}_{2}$

\begin{tabular}{|c|c|c|c|c|}
\hline \multicolumn{2}{|c|}{ Sumber Si/Al } & \multirow{2}{*}{ template } & \multirow{2}{*}{$\begin{array}{l}\% \\
\text { adsorb }\end{array}$} & \multirow{2}{*}{ Referensi } \\
\hline $\mathbf{S i}$ & Al & & & \\
\hline \multicolumn{2}{|c|}{ Zeolite alam } & CTABr & $27,51 \%$ & Hasil penelitian \\
\hline \multicolumn{2}{|c|}{ Zeolite alam } & - & $11,73 \%$ & Hasil penelitian \\
\hline \multicolumn{2}{|c|}{ Zeolite alam } & - & $11,22 \%$ & $\begin{array}{l}\text { Apriyanti } \\
(2012)\end{array}$ \\
\hline \multirow{2}{*}{\multicolumn{2}{|c|}{$\begin{array}{l}\text { Zeolite alam } \\
\text { Zeolite alam }\end{array}$}} & - & $5.00 \%$ & Hamidi (2011) \\
\hline & & - & $3,80 \%$ & Yamliha (2013) \\
\hline LUDOX & $\mathrm{NaAlO}_{2}$ & $\mathrm{TPABr}$ & $43.00 \%$ & $\begin{array}{l}\text { Venkatesh } \\
\text { (2016) }\end{array}$ \\
\hline PSAL & PS & $\mathrm{TPABr}$ & $67,10 \%$ & $\begin{array}{l}\text { Ayala } \quad \mathrm{dkk} . \\
(2014)\end{array}$ \\
\hline TEOS & $\mathrm{NaAlO}_{2}$ & TPAOH & $13,74 \%$ & Liu dkk. (2017) \\
\hline
\end{tabular}

Beberapa penelitian menunjukkan bahwa zeolite alam dapat dimodifikasi menjadi ZSM-5 dengan efisiensi ratarata penjerapan $\mathrm{CO} 2$ sekitar $11 \%$, penambahan template $\mathrm{CTABr}$ dapat meningkatkan efisiensi penjerapan $\mathrm{CO} 2$ dua kali lipat. Berdasarkan hal tersebut pembuatan ZSM-5 dari zeolite alam dengan template $\mathrm{CTABr}$ dapat dipertimbangkan sebagai alternatif pembuatan ZSM-5 yang lebih murah.

\section{Kesimpulan}

Keberhasilan modifikasi zeolit alam menjadi ZSM-5 juga didukung dengan uji SEM dan XRD. Uji XRD menunjukkan bahwa ukuran diameter kisi kristal ZSM-5 lebih besar dari pada zeolit alam yaitu sebesar 37,86 nm sedangkan zeolit alam sebesar 20,38 nm. Selanjutnya, uji SEM menunjukkan bahwa struktur kristal ZSM-5 lebih terlihat jelas dibandingkan dengan zeolit alam. Unjuk kerja zeolit alam dan ZSM-5 dalam proses penjerapan $\mathrm{CO}_{2}$ menunjukkan bahwa ZSM-5 lebih efektif dalam menurunkan kadar $\mathrm{CO}_{2}$. Dengan massa 200 gram ZSM-5 dapat menjerap sebesar $27,5086 \%$ sedangkan zeolit alam dapat menjerap sebesar $11,7306 \%$.

\section{Daftar Pustaka}

Apriyanti E. 2012. Adsorbsi $\mathrm{CO}_{2}$ Menggunakan Zeolit: Aplikasi Pada Pemurnian Biogas. Majalah Ilmiah Universitas Pandanaran. 10 (22).

Ayala F. E., Corella R. C., Pérez A. M., Hernández R. P., and Ramírez-Zamora R. M. 2014. Carbon Dioxide Capture Utilizing Zeolites Synthesized With Paper Sludge And Scrap-Glass. Waste Management \& Research. 32 (12).

Emelda L., Putri S. M., dan Ginting S. 2013. Pemanfaatan Zeolit Alam Teraktivasi untuk Adsorpsi Logam $\mathrm{Cr}^{3+}$. Jurnal Rekayasa Kimia dan Lingkungan, 9 (4).

Hamidi N., Wardana I., dan Widhiyanuriyawan D. 2011. Peningkatan Kualitas Bahan Bakar Biogas Melalui Pemurnian dengan Zeolit Alam. Jurnal Rekayasa Mesin. 2 (3). 
Eksergi, Vol 18, No. 2

ISSN: $1410-394 \mathrm{X}$

Kafillah M., Nurlina, dan Alimuddin A. H. 2018. Sintesis dan Karakterisasi Zeolit Analsim Menggunakan Prekursor Silika dari Limbah Kaca. JKK. 7 (1).

Liu Q., He P., Qian X., Fei Z., Zhang Z., Chen X., Tang J., Cui M., Qiao X., \& Shi Y. 2017. Enhanced CO2 adsorption performance on hierarchical porous ZSM-5 zeolite. ACS Paragon Plus Environment.

Masruroh, Manggara A. B., Papilaka T., dan Triandi R. 2013. Penentuan Ukuran Kristal Lapisan Tipis PZT Dengan Metode XRD Melalui Pendekatan Persamaan Dyebe Scharrer. Jurnal UB.

Ohlin L., Bazin P., Thibault-Starzyk F., Hedlund J., dan Grahn M. 2013. Adsorption Of $\mathrm{CO}_{2}, \mathrm{CH}_{4}$, and $\mathrm{H}_{2} \mathrm{O}$ in Zeolite ZSM-5 Studied Using In Situ ATR-FTIR Spectroscopy. The Journal Of Physical Chemistry.

Petushkov, A., Yoon, S., and Larsen,S.C. 2011. Synthesis of Hierarchical nanocrystalline ZSM-5 with Controlled Particle Size and Mesoporosity. Micropor, Mesopor, Mater. 137(92-103).

Price, Elizabeth C., Cheremisinoff, and Paul N. 1981. Biogas Production and Utilization (Energy technology series). Arbor Science Publishers.

Putro A. L. dan Prasetyoko D. 2007. Abu Sekam Padi Sebagai Sumber Silika Pada Sintesis Zeolit ZSM-5 Tanpa Menggunakan Templat Organik. Akta Kimindo. 3 (1).

Reniaili. 2014. Enceng Gondok Sebagai Biogas yang Ramah Lingkungan. Jurnal Ilmiah TEKNO. 11(1).

Rohayati, KrisnandiY. K., and Sihombing R. 2016. Synthesis of ZSM-5 Zeolite Using Bayat Natural Zeolite as Silica and Alumina Source. International Symposium on Current in Mathematics and Sciences 2016 (ISCPMS 2016).

Venkatesh V., Jaikumar M., and Rajadurai M. S. 2016. $\mathrm{CO}_{2}$ Capture by Using Modified ZSM-5 Zeolite In Diesel Powered Vehicle. IOSR Journal Of Mechanical And Civil Engineering (IOSR-JMCE). 13(102-107).

Yamliha A., Argo B. D., dan Nugroho W. A. 2013. Pengaruh Ukuran Zeolite Terhadap Penyerapan Karbondioksida $\left(\mathrm{CO}_{2}\right)$ Pada Aliran Biogas. Jurnal Bioproses Komoditas Tropis. 1(2).

Yuanita. 2010. Kajian Modifikasi dan Karakterisasi Zeolit Alam Dari Berbagai Negara. Jurdik Kimia UNY. 1956-2010.

Yulianti I. T. 2017. Sintesis ZSM-5 (Zeolite Secony Mobile-5) dari Silika Ampas Tebu (Bagasse) Menggunakan Metode Steam Assisted Conversion (SAC). Skripsi. Bandar Lampung: Fakultas Matematika dan Ilmu Pengetahuan Alam, Universitas Lampung.

Zahrina I., Yelmida, dan Akbar F. 2010. Sintesis ZSM-5 dari Fly Ash Sawit Sebagai Sumber Silika. Seminar Nasional Fakultas Teknik-UR. 